\title{
The effectiveness of emotion regulation group training in improving quality of life and mitigating emotion regulation difficulties of women during pregnancy
}

\author{
Samira Ameli ${ }^{1}$, Maryam Aslzaker ${ }^{2}$, Saghar Salehpour $^{3}$, Mahdi Jafari ${ }^{2}$ \\ 1-MSc. Student of Clinical Psychology, Department of Clinical Psychology, Shahid Beheshti University of Medical \\ Sciences, Tehran, Iran. \\ 2- Assistant Professor, Department of Clinical Psychology, Shahid Beheshti University of Medical Sciences, \\ Tehran, Iran. \\ 3- Professor, Department of Obstetrics and Gynecology, Shahid Beheshti University of Medical Sciences, Tehran, \\ Iran. \\ Corresponding Author: Mahdi Jafari_Ｅ-mail:drmjafari@sbmu.ac.ir
}

Received: $25 / 10 / 2020$

Accepted: 09/01/2021

\begin{abstract}
Introduction: While pregnancy and childbirth can be considered as a natural bodily function for women, it is still an experience that increases their vulnerability to a variety of physical and psychological problems. Therefore, it seems necessary to improve their quality of life and mental health.
\end{abstract}

Aim: The present study was conducted in order to evaluate the effectiveness of emotion regulation group training for improving the quality of life and mitigating emotion regulation difficulties of pregnant women.

Method: The current study is a quasi-experimental random study with a pretest-posttest and follow-up design. The statistical population of the study includes all pregnant women in Tehran in 2018, and the sample includes 39 pregnant women, selected based on a targeted sampling method. The Short-Form Quality of Life questionnaire and the Difficulties of Emotion Regulation Scale were used. The emotion regulation group training was administered to the intervention group in 8 sessions. The results were analyzed using repeated measures ANOVA in SPSS-24 software application.

Results: The data analysis indicated that the mean scores of quality of life in the intervention group ( $M=58.13)$ increased compared to the control group $(M=38.25)$. Moreover, the mean scores of DERS in the intervention group in the post-test stage $(\mathrm{M}=77.33)$ significantly decreased at the 0.001 level compared to the pre-test stage $(\mathrm{M}=92.87)$ and the follow-up period $(\mathrm{M}=72.27)$.

Conclusion: Emotion regulation group training can be effective for improving the quality of life of pregnant women and mitigating their emotion regulation difficulties.

Keywords: Emotional regulation, Quality of life, Pregnancy

How to cite this article : Ameli S, Aslzaker M, Salehpour S, Jafari M. The effectiveness of emotion regulation group training in improving quality of life and mitigating emotion regulation difficulties of women during pregnancy. Shenakht Journal of Psychology and Psychiatry. 2021; 7 (6): 28-42 .URL: http://shenakht.muk.ac.ir/article-1-945-en.pdf 


\title{
اثربخشى آموزش تنظيم هيجان تروهى بر بهبود كيفيت زندكى

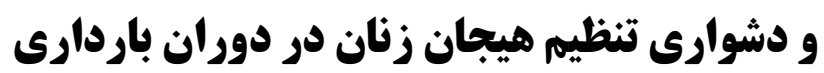

\author{
سميرا عاملى '، مريم اصل ذاكر '، ساغر صالحيورّ، مهدى جعفرى' \\ ا. ادانشجوى كارشناسى ارشد، گروه روانشناسى بالينى، دانشكاه علوم بز شكى شهيد بهشتى، تهران، ايران.

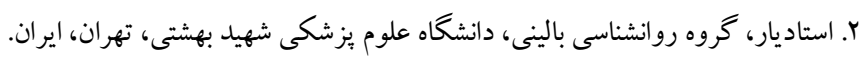

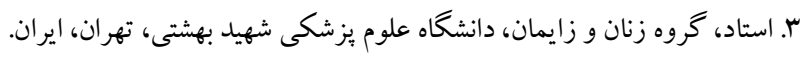
ايميل: drmjafari@ sbmu.ac.ir مولف مسئول: مهدى جعفرى

مقدمه: باردارى و زايمان يك عملكرد طبيعى براى زنان محسوب مىشود؛ ولى در عين حال تجربهاى است كه آسيب يذيرى آنان را

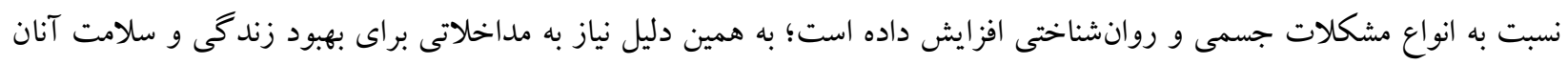
ضرورى به نظر مىرسد. هدف: مطالعه حاضر به منظور تعيين اثربخشى آموزش گروهى تنظيم هيجان بر بهبود كيفيت زندگى و دشوارى تنظيم هيجان زنان باردار انجام شد.

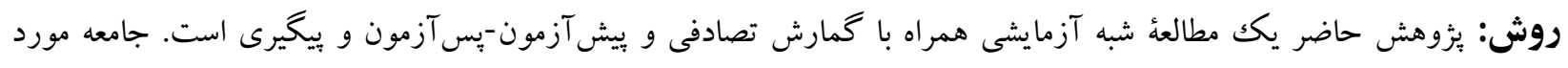

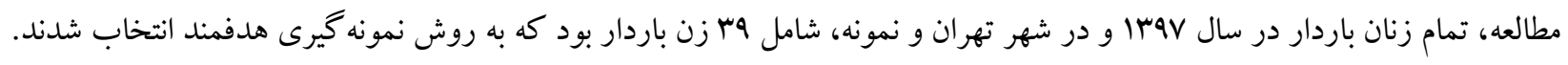

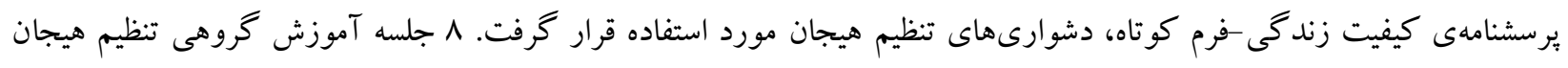

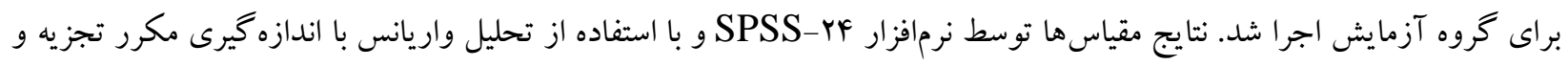
تحليل شد.

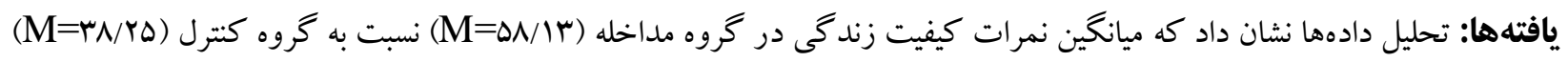

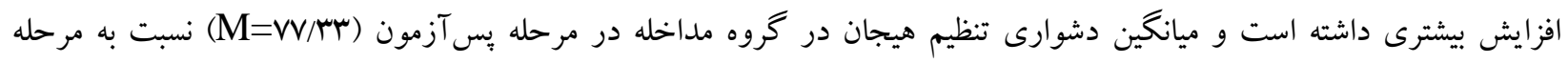

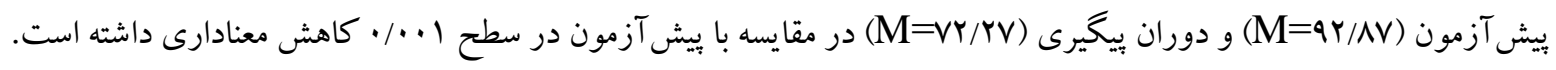
نتيجه گيرى: آموزش گروهى تنظيم هيجان مى تواند در بهبود كيفيت زندگى و دشوارى تنظيم هيجان زنان باردار مؤثر باشد. كليدوازهها: تنظيم هيجانى، كيفيت زندگى، باردارى 
توصيف ميزان سلامت فرد، جنبه عينى نيز مهم است؛ اما مقدمه انتظارات و دريافتهاى ذهنى فرد است كه بيانكر كيفيت زندكى واقعى تجربه شدهى اوست (تركان، بِارساى،

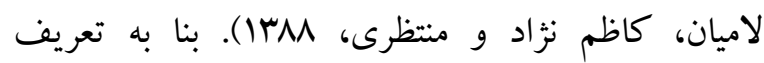
سازمان بهداشت جهانى، كيفيت زندكى، دركى افراد از موقعيت خود در زندكى از نظر فرهنگك، سيستم ارزشى كه در آن زندگى مى كنند، اهداف، انتظارات، استانداردها و اولويت هايشان است. بس موضوعى كاملاً

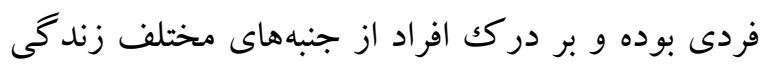

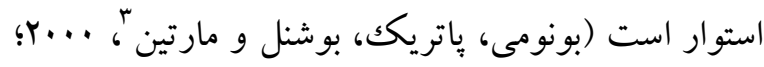
بيخى زاده، شريفى، جواديور و جمالى، وهب ا). شواهد نشان مىدهد كه باردارى علاوه بر ايجاد تغييرات قابل ملاحظه در وضعيت سلامت جسمى و روانى زنان،

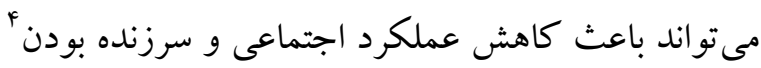

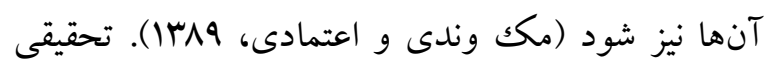
ديخر نشان داد كه حاملكَى با تغييرات قابل ملاحظهاى هم در وضعيت سلامت روانى و هم در سلامت فيزيكى همراه است. همجينين عملكرد اجتماعى و سرزنده بودن در زنان حامله طبيعى كمتر از بقيه افراد جامعه است

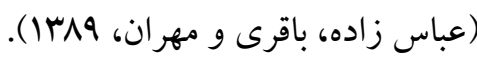
با توجه به آنجه كفته شد، تغييرات ايجاد شده در وضعيت جسمانى و روانى زنان باردار غيرقابل جشميوشى است و يكى از راههاى مؤثر مقابله با اختلالات اين دوران استفاده وناه از روشهاى غير دارويى است (روحه، سالملا-آرو،

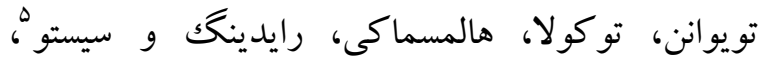
ها (Y). در سالهاى اخير، نقش درمانهاى روانشناختى به ويزه نقش يردازش و تنظيم هيجانى در بهبود

3 - Bonomi, Patrick, Bushnell, \& Martin

4 - Vitality

5- Rouhe, Salmela-Aro, Toivanen, Tokola, Halmesmäki, Ryding, Saisto

1- Pregnancy

${ }^{2}$ - Cattaruzza 
به كار مىرود. ياسخ هاى هيجانى اطلاعات مهمى درباره تجربه فرد در ارتباط با ديخران فراهم مى كنند. (ستاريور،

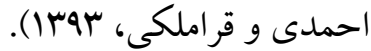
نظريه هاى مختلف بر سر اين موضوع توافق دارند كه تنظيم هيجان كار آمد، شامل مهارتهاى مربوط به () آكاهى و ارزيابى هيجانها Y) تنظيم هيجانها ب) استفاده انطباقى (سازش يافته) از هيجانهاست (بر كينگك، يوي،

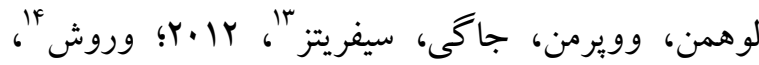
|l(Y). به نظر مىرسد نقص در تنظيم هيجان با ايجاد و حفظ اشكال مختلف آسيب روانى مرتبط باشد (بر كينك

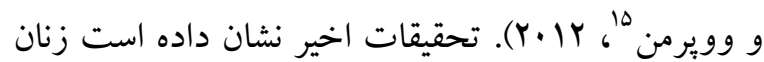
باردارى كه در شناسايى و وصف احساسات و هيجانات خود مشكل دارند، دامنه وسيعى از آسيبشناسى روانى را نشان مىدهند (كيلانىفر و دلاور، وهسا). با قبول اين نكته كه درك افراد از كيفيت زندكى از باورها و فرهنك هاى آنان متأثر است (زاهدى و دريس، |وس|) و نكرش مثبت نسبت به زندگى در بالا بردن كيفيت زندكى زنان در دوران باردارى مؤثر است (عباس زاده، باقرى و مهران، وMA9)، به نظر مىرسد كه ارتقاى سلامت روان زنان باردار به عنوان يكى از اولويتهاى بهداشت عمومى مطرح باشد (زاهدى و دريس، اهب|)؛ لذا به منظور ارتقاء سطح سلامت روان مادران باردار و به تبع آن فرزندانشان و همجِنين ترفيع كيفيت زندگى آنان، اين بثزوهش با هدف دستيابى به نقش راهبردهاى تنظيم هيجان در بهبود كيفيت زندكى و دشوارى تنظيم هيجان انجام شد.

${ }^{13}$ - Berking, Poppe, Luhmann, Wupperman, Jaggi, Seifritz

${ }^{14}$ - Wrosch

${ }^{15}$ - Berking \& Wupperman
راهبردهاى تنظيم هيجان و مراقبت از خود در انواع گوناكونى از اختلالات مورد توجه قرار گرفته است (سلوان، هال، مولدينگ، بريس، ميلدرد و ستيكر'،

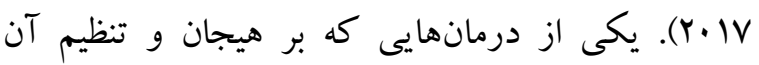
متمر كز است آموزش تنظيم هيجان' است (بارت و

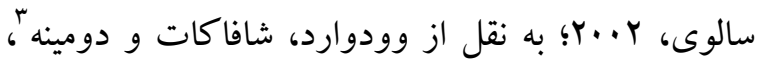
19 • (Y). تنظيم شناختى -هيجانى راهبردهايى است كه افراد در شرايط يريشانى به كار مىبرند تا هيجانهاى خود را

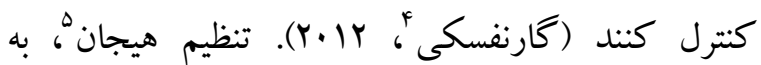
معناى كاهش و تنظيم هيجان منفى و نحوه استفاده از هيجانات است و به توانايى فهم هيجانات، تعديل تجربه و ابراز هيجانات اشاره دارد (منين، هيمبرك، تورك و و

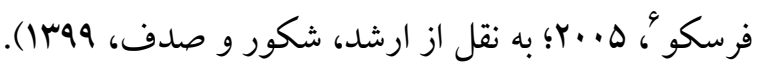
بررسى متون و مطالعات روانشناختى نشان مىدهد كه تنظيم هيجان عامل مهمى در تعيين سالامتى و كيفيت

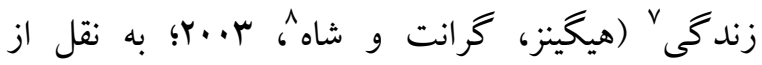

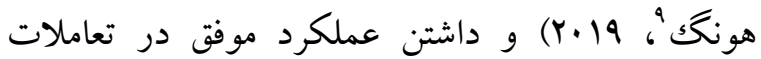
اجتماعى است (صابر، تهرانى، شجاعى زاده، ملكى، اسفندياريور، بوسا). الكوى فرآيند تنظيم هيجان را كراس "'، يسشنهاد كرده است (كراس و جان "'، ب...r؛ به نقل از روز گونجيكك و الهاى با، 19 •r). بر اساس الكوى كراس، تنظيم هيجان شامل تمام راهبردهاى آكاهانه و غير آكاهانهاى مىشود كه براى افزايش، حفظ و كاهش مؤلفه هاى هيجانى، رفتارى و شناختى يكك يّاسخ هيجانى

\footnotetext{
1- Sloan, Hall, Moulding, Bryce, Mildred, Staiger

2 - Emotion Regulation Training

3 - Woodward, Shaffakat, and Dominé

${ }^{4}$ - Garnefski

5 - Emotion Regulation

6 - Mennin, Heimberg, Turk, \& Fresco

${ }^{7}$ - Quality of Life

${ }^{8}$ - Higgins, Grant, \& Shah

9 - Hong

${ }^{10}$ - Gross JJ

${ }^{11}$ - Gross \& John

${ }^{12}$ - Rozgonjuk, and Elhai
} 
و ץ نفر از گرووه مداخله به دليل دارا بودن ملاككهاى

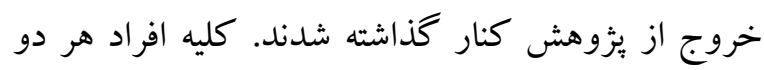
كروه مداخله و گروه كنترل تمامى اطلاعات يزوهش، مراحل دوره آموزشى را توسط يثزوهشخر دريافت كردند. اعضاى گروه مداخله كه به صورت تصادفى در اين گروه

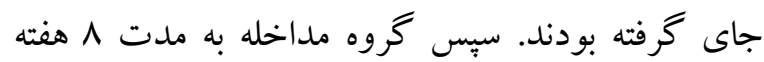
تحت آموزش تنظيم هيجان گروهى مطابق با يروتكل

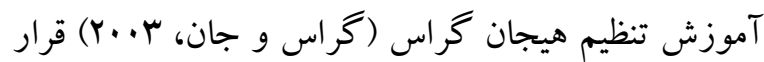
كرفت كه خلاصه آن در جدول ارائه شده است. آموزشى كه براى گروه كنترل ارائه شده، شامل اطلاعاتى

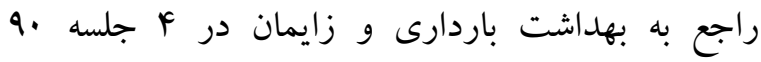
دقيقهاى بود. در پيايان مداخله و همجينين دو ماه بعد از

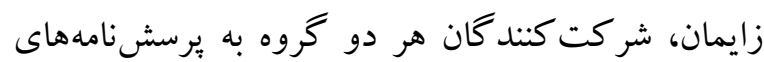
مذكور مجدداً يِاسخ دادند، سپس اطلاعات به دست

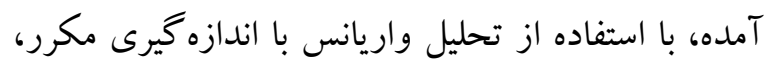

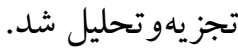

يثزوهش حاضر يكك مطالعهُ شبه آزمايشى داراى كروه كنترل همراه با كمارش تصادفى و و ييش آزمون -

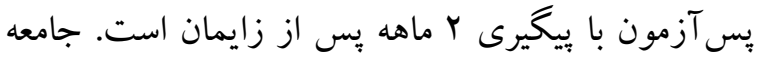
مورد مطالعه، شامل كليه زنان باردار شهر تهران در سال Vج"ا و نمونه مورد مطالعه، هץ نفر از زنان باردارى كه در سال 9V به كلينيك زنان و زايمان مركز بزشكى، آموزشى و درمانى آيتالله طالقانى مراجعه كردهاند. نمونها با روش نمونه گيرى هدفمند انتخاب شده و به طور تصادفى در دو گروه مداخله و كنترل گمارده شدند. ملاككهاى ورود در اين بثزوهش شامل داشتن سن 11 -

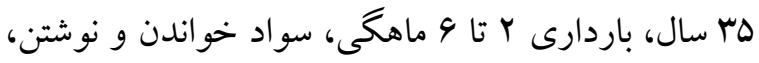
عدم وجود سابقهى بيمارىهاى مزمن و اختلال روانشناختى عمده و مصرف دارو بود؛ همينطور ملاككهاى خروج عبارت بودند از: غيبت بيش از م جلسه

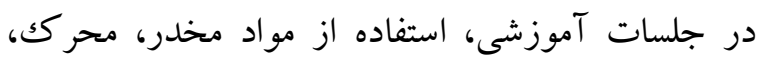
الكل، سيكار در طول بثزوهش و تجربهى استرس عمده يا بيمارى جسمانى. در طول بزوهش ه نفر از خروه مداخله

\begin{tabular}{|c|c|c|c|}
\hline دستور جلسه & اهداف جلسه & موضوع جلسه & 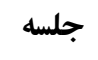 \\
\hline 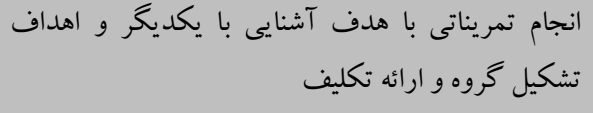 & 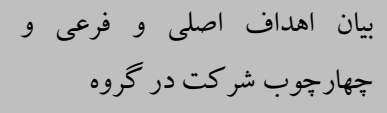 & آشنايى و ارتباط & 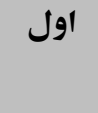 \\
\hline هرور تكليف و تعريف هيجان و تفكيك ابعاد مختلف هر & ارائه آموزش هيجانى & انتخاب موقعيت & 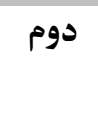 \\
\hline 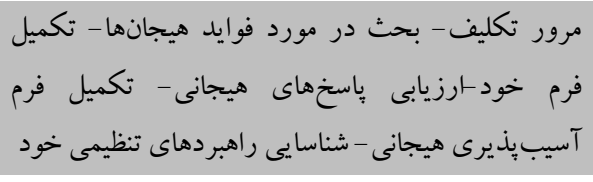 & و ارزيابى ميزان آسيبيذيرى هيجانى & انتخاب موقعيت & 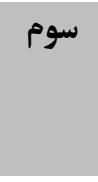 \\
\hline كرور اهداف فرديف- جلو گيرى از انزواى اجتماعى - فهرست اجتماعى - آموزش مهارتها & هيجان ايجاد تغيير در موقعيت برانگيزانده & اصلاح موقعيت & 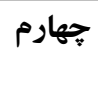 \\
\hline به اعضار تكاليف، معرفى مدل و آموزش مهارت تغيير توجه & آموزش مهارتهاى تغيير توجه & كسترش توجه & ل عنجم \\
\hline مرور تكليف - كفتكو در مورد نقش ذهن، پردازش & و ميزان تجربه & شناسايى ياسخ & 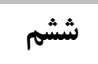 \\
\hline
\end{tabular}




\begin{tabular}{|c|c|c|c|}
\hline ذهنى و افكار و شناسايى ارزيابىهاى غلط & 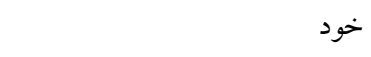 & & \\
\hline 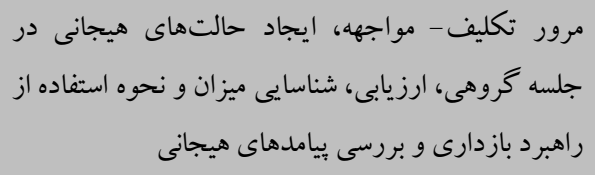 & 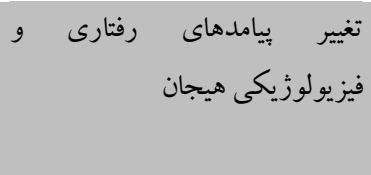 & تعديل باسخ & 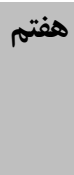 \\
\hline برائه گزارش از نحوه انجام تكليف جلسه قبل - ارزيابى - & 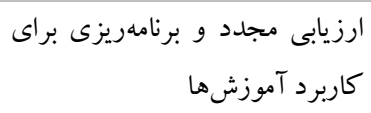 & ارزيابى و كاربرد & 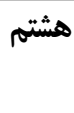 \\
\hline
\end{tabular}

برخوردار است (ييلكونيس'، 19 19ب؛ كانسيان، سوزا،

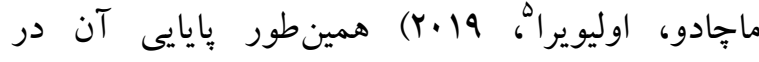

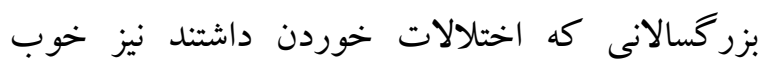

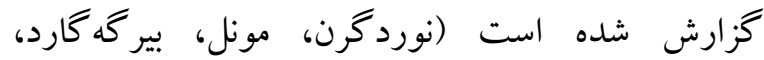

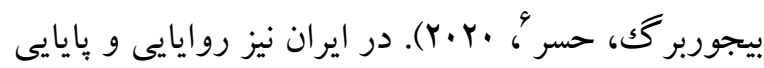
اين تيرسشنامه توسط اسدى مجره و اكبرى مورد بررسى

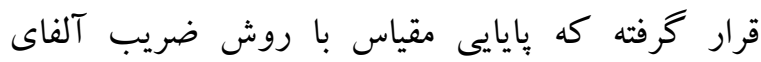
كرونباخ، 91/· به دست آمد (اسدى مجره و اكبرى،

. (I) MaV

كيفيت زندكى -فرم كوتاه' إين برسشنامه توسط وير و شربورن^(1994) و در سال 1994 ساخته شده است و و شامل هشت خرده مقياس عملكرد جسمى، ايفاى نقش جسمى، دردهاى بدنى، سلامت عمومى، انرزى و و

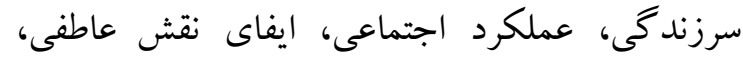

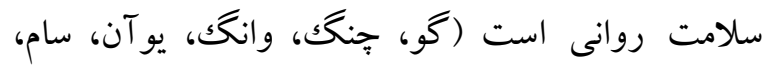

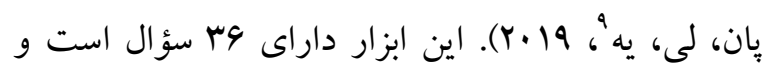
كيفيت زندگى را در ^ حيطه مورد بررسى قرار مىدهد كه عبارتاند از؛ عملكرد جسمى، محدوديت در ارتباط با مشكلات جسمى، درد جسمى، وضعيت سلامت عمومى، نشاط، عملكرد اجتماعى، محدوديت در برقرارى ارتباط با مسائل روانى و سلامت روانى. دو مقياس كلى

4. Pilkonis

5 - Cancian, Souza, Machado, \& Oliveira

6- Nordgren, Monell, Birgegård, Bjureberg, \& Hesser

7. Quality of life-SF-36 short

${ }^{8-}$ Ware \& Sherbourne

${ }^{9}$ - Gu, Cheng, Wang, Yuan, Sam, Pan, Li, and Ye يرسشنامه يا فرم اطلاعاتى: يرسشنامه ويز كىهاى جمعيت شناختى: شامل سن، ترتيب زايمان (تعداد باردارىهاى قبلى)، مدتزمان باردارى، جنسيت جنين، نوع زايمان قبلى، ميزان تحصيلات، وضعيت اشتغال، تعداد فرزند، سابقه بيمارى بزشكى يا روانيز شيكى. يرسشنامه دشوارىهاى تنظيم هيجان'؛ اين برسشنامه در

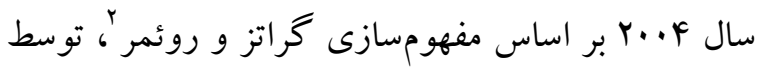

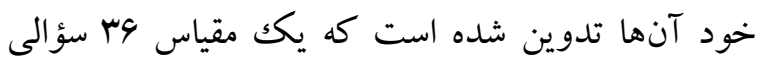
است كه الكوهاى تنظيم هيجان را در قالب شش خرده مقياس (عدم يذيرش، يّاسخهاى هيجانى، اشكال در مشاركت رفتارهاى منتهى به هدف، مشكلات كنترل تكانه، كمبود آكاهى هيجانى، محدوديت در دستيابى به راهبردهاى تنظيم هيجان و كمبود صراحت هيجانى) مىسنجد و بيش از هر جيز بر مشكلات در تنظيم هيجان،

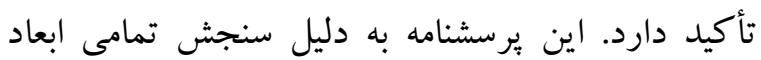
تنظيم هيجان، استفاده بسيارى در يزوهشها دارد. شيوه

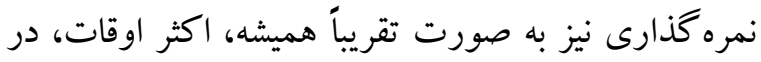
نيمى از موارد، گاهى اوقات و تقريباً هر زز است (لاسى،

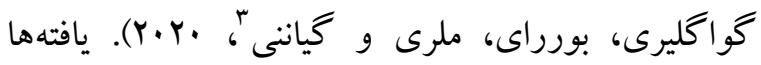
نشان مىدهند كه اين مقياس از همسانى درونى بالايى

\footnotetext{
1- Difficulties of Emotion Regulation Scale (DERS)

2- Gratz, Roemer

3 - Lausi, Quaglieri, Burrai, Mari, \& Giannini
} 
در اين مطالعه هM نفر از مادران باردار شركت داشتند كه در دو گروه مداخله و كنترل به صورت تصادفى گماشته شدند. در طول مراحل اجرايى ئزوهش ه نفر از گروه مداخله و r نفر از گروه كنترل خارج شدند؛ بنابراين تعداد شركت كنندهايى كه اطلاعات به دست آمده از آنها محاسبه و تحليل شد شامل گروه مداخله متشكل از ها نفر و كروه كنترل 19 نفر بود. مادران باردار شركت كننده در اين ئزوهش بين \| تا ها سال سن داشتند كه اكثريت (4ه درصد) آنها هم در گروه كنترل و هم در

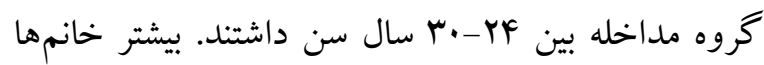
(4.9 درصد) داراى تحصيلات دييلم و بالاى دييلم بودند، همجنين اكثريت آنها خانه دار (90 درصد) بودند. تعداد مادرانى كه براى بار دوم يا بيشتر باردار شده بودند بيشتر

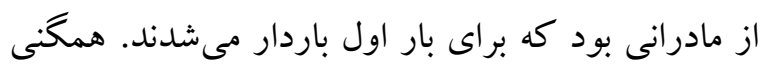

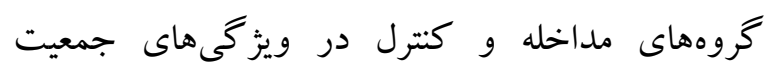
شناختى با استفاده از تست خى دو و تست دقيق فيشر مورد آزمون قرار گرفت كه در جدول قابل مشاهده است.
نيز از ادغام ^ مقياس ذكر شده به دست مى آيند كه

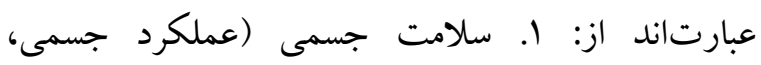
محدوديت در ارتباط با مشكلات جسمى، درد جسمى، وضعيت سلامت عمومى) و r. سلامت روانى (نشاط، عملكرد اجتماعى، محدوديت در برقرارى ارتباط با مسائل روانى و سلامت روانى). نمره كيفيت زندكى در حيطهاى مختلف از · تا . . ا نمره كذارى مى شود. نمره بالاتر نشان دهنده كيفيت زندگى بالاتر است. بررسى ويز گیىهاى روانسنجى نشان داد كه اين برسشنامه، روايى سازه خوبى دارد و همجِين اعتبار ملاكك و اعتبار همخرايى نيز در حد قابلقبول گزارش شد (لين، يو،

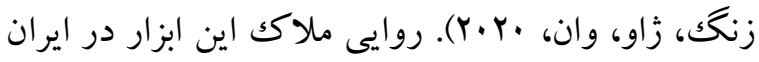

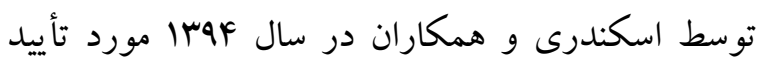
قرار گرفته است. ضريب آلفاى كرونباخ ه9/· و ضريب پايايى آزمون مجد در دو بار اجراو به فاصله Y هفته، در تمامى ابعاد بيشتر از •9/ • گزارش شد (اسكندرى، هروى

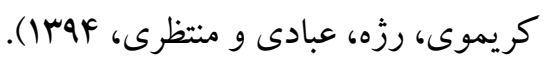

\section{يافته ها}

\begin{tabular}{|c|c|c|c|c|}
\hline تست دقيق فيشر & سطح معنادارى & درجه آزادى & خى دو & جمعيت شناختى ويزى \\
\hline & .194 & r & $\cdot / \wedge 9$ & سن مادران \\
\hline & $\cdot / \wedge \Delta$ & r & . & تحصيلات مادران \\
\hline$\cdot / 49$ & $\cdot / \mu r$ & 1 &.$/ 99$ & شغل مادران \\
\hline \multirow[t]{2}{*}{$\cdot / A V$} & ג & 1 & $\cdot / \mathrm{NA}$ & تعداد باردارى \\
\hline & $.19 \mathrm{~V}$ & r & $\cdot / \mathrm{va}$ & تعداد فرزند \\
\hline$\cdot / N r$ & $\cdot / \Delta \Lambda$ & 1 & $\cdot / \mu 1$ & جنسيت جنين \\
\hline$\cdot / N Y$ & $\cdot / \Delta 9$ & 1 & $\cdot / 79$ & مدت باردارى \\
\hline
\end{tabular}


(p=•/9V)

(p=•/ه9)

حجم نمونهى كم با استفاده از آزمون شاييرو ويلكك مورد

آزمون قرار كرفت كه نتايج در جدول آورده شده است.
نتايج تست خح دو و تست دقيق فيشر نشان داد كه دو كروه مداخله و كنترل در ويز گیىهاى جمعيت شناختى تفاوت معنادارى ندارند (با سطح معنادارى براى سن مادران (p=•/94)، تحصيلات

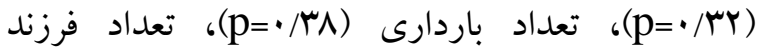

جدول ب نتايج آزمون شاييرو -ويلك مؤلفههاى كيفيت زندكى و دشوارى در تنظيم هيجان زنان در دو كروه مداخله و كنترل مداخله

\begin{tabular}{|c|c|c|c|c|c|c|c|}
\hline سطح معنادارى & درجه آزادى & Tاره & سطح معنادارى & درجه آزادى & Tاره & زمان & متغير \\
\hline$\cdot / V^{F}$ & 19 & $\cdot / 99$ & .194 & 10 & $\cdot / 99$ & بيش آزمون & كيفيت زندكى \\
\hline$\cdot / 4 \Delta$ & 19 & $\cdot / 90$ & טמ/. & 10 & $\cdot / 9 F$ & يֶس آزمون & \\
\hline$\cdot 194$ & 19 & $\cdot / 99$ & $\cdot / F V$ & 10 & $\cdot / 90$ & بيخيرى & \\
\hline$\cdot / 9 F$ & 19 & $\cdot / 91$ & $\cdot / \mu r$ & 10 & $\cdot / 94$ & ي ييش آزمون & دشوارى در تنظيم \\
\hline$\cdot / 4$ & 19 & $\cdot / 9 F$ & ט ט & 10 & $\cdot / 9 F$ & يس آزمون & هيجان \\
\hline.$/ 91$ & 19 &.$/ 91$ & $\cdot / 4 A$ & 10 & $\cdot / 90$ & يِيخيرى & \\
\hline
\end{tabular}

مفروضه نرمال بودن برقرار بود. شاخصهاى توصيفى كيفيت زندگى و دشوارى در تنظيم هيجان براى كروههاى مداخله، كنترل و كل افراد در جدول نشان داده
نتايج آزمون شاييرو -ويلك حاكى از اين بود كه در هر دو گروه مداخله و كنترل مؤلفههاى كيفيت زندكى و دشوارى در تنظيم هيجان داراى توزيع نرمال بودند و اين مقدار براى هيج كدام از مؤلفهها معنادار نبود؛ بنابراين

جدول ع آمارههاى توصيفى كيفيت زندكى و دشوارى در تنظيم هيجان زنان در دو كروه مداخله و كنترل

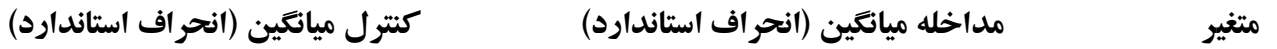

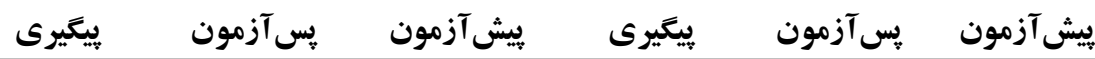

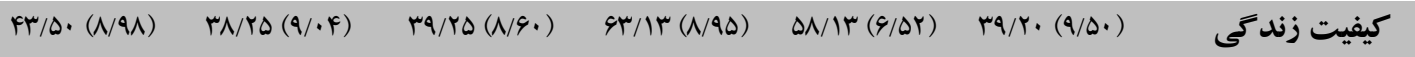

دشوارى تنظيم هيجان

دشوارى در تنظيم هيجان نيز حاكى از كاهش نمرهى

دشوارى در تنظيم هيجان زنان در دورهى باردارى و بِ

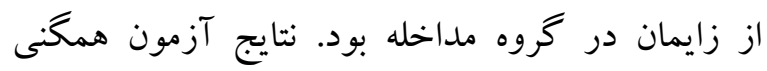

واريانس (لوين) در جدول گزارش شده است.
همانطورى كه در جدول قابل مشاهده است، ميانگين

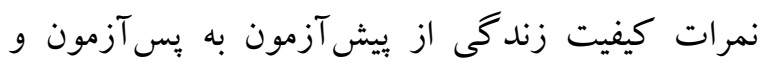
بيخيرى در خروه مداخله افزايش داشته در حالى كه تغيير جندانى در كروه كنترل مشاهده نمىشود. نتايج براى

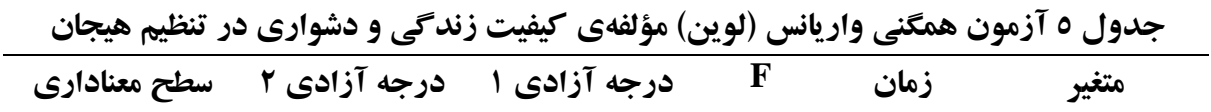




\begin{tabular}{|c|c|c|c|c|c|}
\hline$\cdot / \Delta \Delta$ & rq & 1 & $\cdot / \mathrm{HV}$ & ييش آزمون & كيفيت زندىى \\
\hline$\cdot / r q$ & rq & 1 & $1 / 10$ & بِ آزمون & \\
\hline$\cdot / \Delta F$ & $r q$ & 1 & $\cdot / \mu$ & بيشيرى & \\
\hline$\cdot / \mathrm{AV}$ & rq & 1 & $\cdot / \cdot r$ & ييش آزمون & دشوارى در \\
\hline • & rq & 1 & $1 / 9$ & يس آزمون & تنظيم هيجان \\
\hline .194 & $r q$ & 1 & $\cdot / r$ & بيخيرى & \\
\hline
\end{tabular}

است. نتايج تحليل واريانس تكى متغيرى با اندازه مكرر (طرح يكك بين-يك درون) در مؤلفه كيفيت زندكى و دشوارى در تنظيم هيجان در جدول ارائه شده

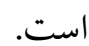

همانطورى كه در جدول نشان داده شده است بين دو كروه در مؤلفههاى كيفيت زندگى و دشوارى در تنظيم هيجان در سه مرحله اندازهيرى تفاوت معنادارى وجود ندارد. بدين معنى كه مفروضهى همخنى واريانس برقرار

جدول 7 نتايج تحليل واريانس تك متغيرى با اندازهيرى مكرر (طرح يك بين-يك درون) در مؤلفه كيفيت زندكى و دشوارى در تنظيم هيجان

\begin{tabular}{|c|c|c|c|c|}
\hline ضريب تأثير & سطح معنادارى & Tاره F & متغير ها & منبع اثر \\
\hline .199 & $\cdot / \cdot \cdot 1$ & $90 / V^{F}$ & كيفيت زندگى & اثر بين كروهى \\
\hline$\cdot / q V$ &.$/ . .1$ & $r \varphi / \cdot \Lambda$ & دشوارى در تنظيم هيجان & \\
\hline$\cdot / 4$ & $\cdot / \cdot .1$ & $19 / \pi r$ & كيفيت زندگى & اثر درون آزمودنى \\
\hline$\cdot / 49$ & $\cdot / \cdot \cdot 1$ & $M / Y F$ & دشوارى در تنظيم هيجان & \\
\hline$\cdot / r$ & $\cdot / \cdot 1$ & $\mid r / r 9$ & كيفيت زندگى & اثر تعامل كروه×زمان \\
\hline$\cdot / \mu \Lambda$ &.$/ .1$ & $1 N / \cdot V$ & دشوارى در تنظيم هيجان & \\
\hline
\end{tabular}

داد كه دو گروه مداخله و كنترل از ييش آزمون به يس آزمون و بيش آزمون با بيخيرى تفاوت معنادار دارند (p=•/・1) نبود (p=/YV). با توجه به اين يافتها مىتوان نتيجه كرفت كه تغييرات ميانگين دشوارى در تنظيم هيجان زنان در طى زمان در بين دو گرووه از بيش آزمون به بس آزمون و از بيش آزمون به بيخيرى تفاوت معنادارى

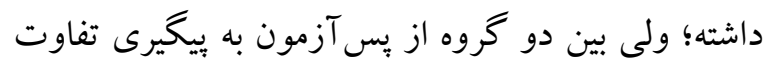

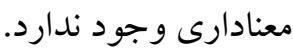
همجنين اثر متقابل گروه×زمان در متغير كيفيت زندگى

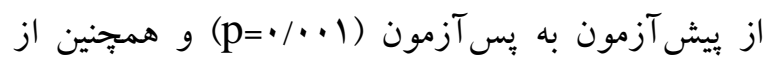

نتايج آزمون تحليل واريانس تكك متغيرى نشان داد اثر اصلى بين گروهى (مداخله و كنترل) در متغير كيفيت

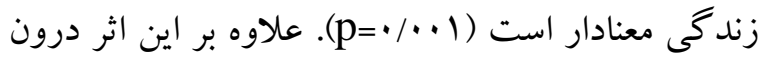
آزمودنى (زمان) و اثر متقابل گروه×زمان نيز در متغير

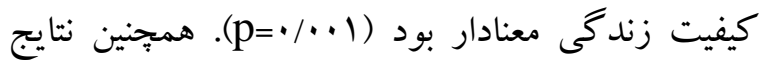
آزمون تحليل واريانس تكك متغيرى نشان داد اثر اصلى بين گروهى (مداخله و كنترل) در متغير دشوارى در تنظيم

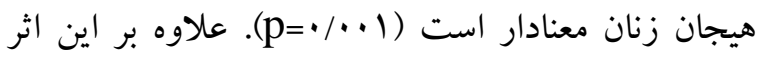
درون آزمودنى (زمان) و اثر متقابل گروه×زمان نيز در

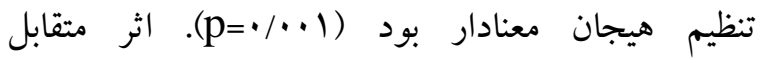
كروه×زمان، در متغير دشوارى در تنظيم هيجان نيز نشان 
ميانگين كيفيت زندگى در سه مرحلهى اندازهگيرى در

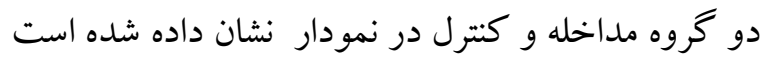
كه حاكى از اين است كه نمرات در گرووه كنترل از بيش آزمون به بِ آزمون كاهش جزئى و از بِ بس آزمون

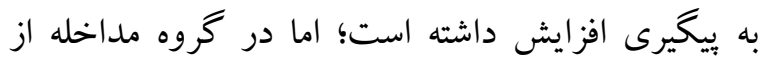
بيش آزمون به بِ آزمون و بيشيرى افزايش داشته است.

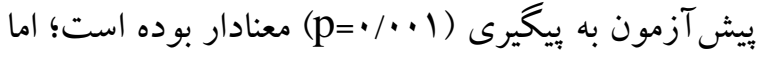

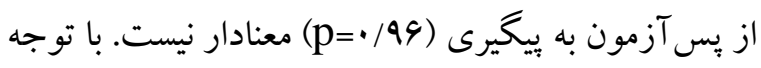

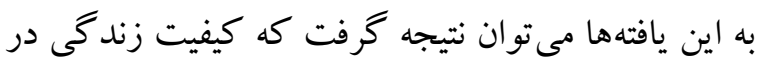
كروه مداخله در طى زمان نسبت به كروه كنترل افزايش معنادارى داشته است (جدول ).

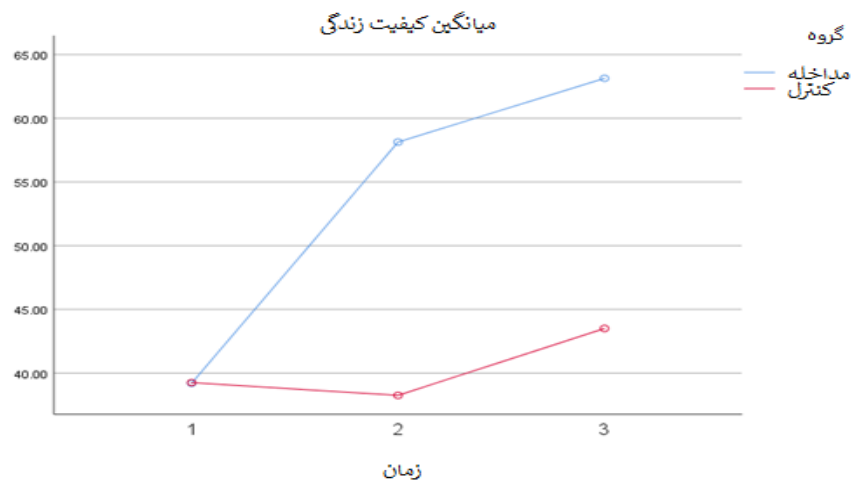

نمودار ا ميانكين كيفيت زندكى دو كروه مداخله و كنترل در سه مرحله اندازهكيرى

ميانگين دشوارى در تنظيم هيجان زنان در دورهى افزايش جزئى و از بس آزمون به بيخيرى كاهش داشته

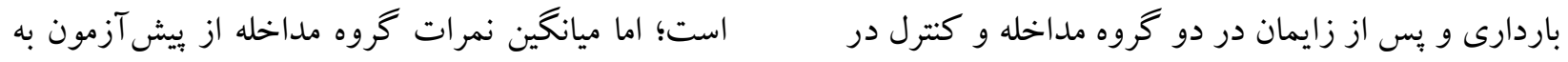

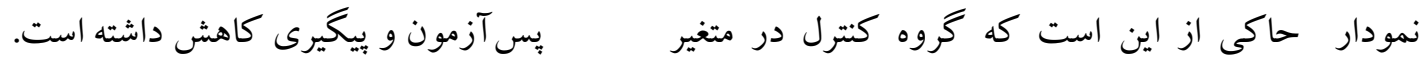
دشوارى تنظيم هيجان از يِيش آزمون به پِ بس آزمون

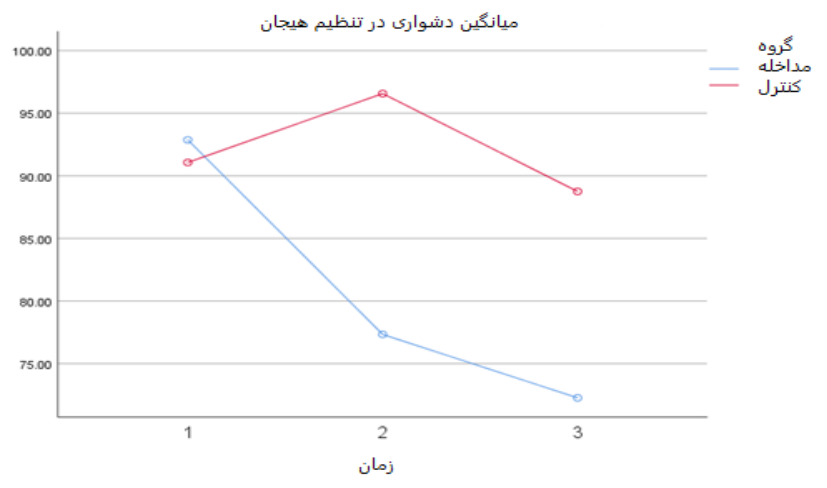

نمودار r ميانكين دشوارى در تنظيم هيجان زنان در دو كروه مداخله و كنترل در سه مرحله اندازه 
جسمانى و روانشناختى روبرو هستند كه اين خود موجب احساس تنش بيشترى مىشود؛ اما با آموزش تنظيم هيجان و راهبردهاى كار آمد تنظيم هيجان، زنان باردار قادر به بازشناسى هيجانات و موقعيت اضطراب زا شدهاند و بهجاى واكنشهاى ناكارآمد اجتناب از موقعيت يا واكنش ناگهانى با تجربه هيجان آنى، به نام گذارى هيجانات و اعتباربخشى به آنان مى بردازند. در واقع زنان باردار با انجام تمرينهاى مختلف عملى و شناختى تنظيم هيجان، اين سطح از آكاهى را تجربه مى كند كه تجربه، افكار، واكنشها و هيجانات آنها در موقعيت خاص جيست. آكاهى از هيجانهاى كلامى و غير كلامى و ارزيابى آنها در خود يا ديخران مىتواند موجب تمايل به ياسخدهى ارادى به منظور تعديل و استفاده از هيجانها شود. تنظيم هيجانها مستلزم مديريت

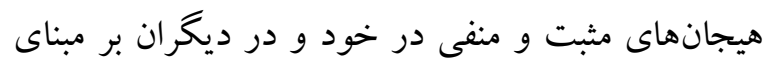

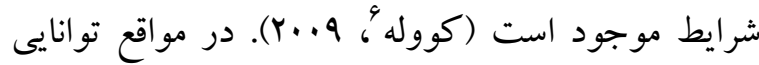
تنظيم پاسخ هاى هيجانى به محر كات بيرونى و درونى زمينه سلامت روان و داشتن كاركرد شايسته در طول

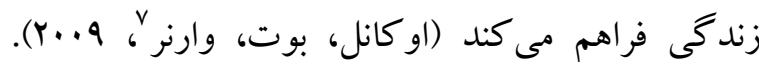
تجربه اضطراب، فرد، هيجانات خود و ديگران ران ران شناسايى مى كند، واكنشهاى احتمالى را بيشبينى كرده و مناسبترين واكنش را در برابر اتفاقات از خود نشان

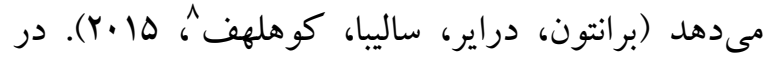
حالى كه جنين مادرى با شناخت هيجانات خود و بيان كلامى هيجانات، مىتواند واكنش كارآمدترى را در مقابل اين اضطراب داشته باشد يا حتى اضطراب و افسردگى كمترى را تجربه بكند (مين، يو، لى و جائى'،

6- Koole

7- O'Connell, Boat, \& Warner

${ }^{8}$ - Brunton, Dryer, Saliba, \& Kohlhoff

${ }^{9}$ - Min, Yu, Lee, \& Chae
اين يزّوهش با هدف دستيابى به نقش راهبردهاى تنظيم هيجان در بهبود كيفيت زندكى و دشوارى تنظيم هيجان انجام شد. جنانجه مشاهده شد برنامه آموزشى تنظيم هيجان اجرا شده توانسته است، كيفيت زندكى زنان در دوران باردارى رابه ميزان قابل قبول افزايش دهد و از افت كيفيت زندگى در دوران باردارى و بس از زايمان جلو گيرى كند. با در نظر گرفتن اينكه كيفيت زندكى از ذهن فرد و ادراكى كه از زندكى خود دارد، تأثير مى يذيرد مى توان تبيين كرد كه بهبود تنظيم هيجان توانسته است ادراكك فرد از زندگى و كيفيت آن را بهبود بخشد. اين تغيير نشان مىدهد كه كيفيت زندكى به صورت مستقيم مىتواند با حالات هيجانى و روانشناختى افراد تغيير يابد (وروش، 11) هيجان، فرد با آكاهى از هيجانات منفى و مثبت و آمادهازى براى بذيرش آنها، زمينه را براى بروز و و تكرار افكار منفى كاهش مىدهد.

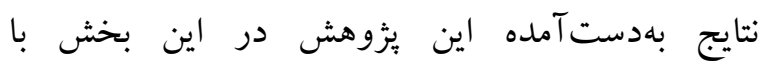

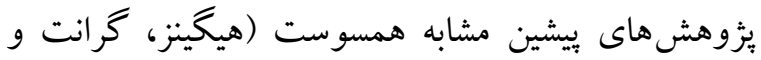

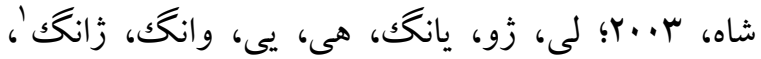

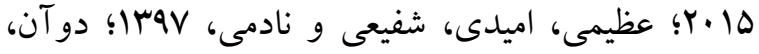

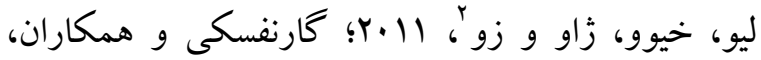

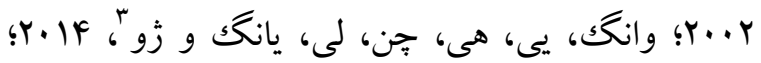

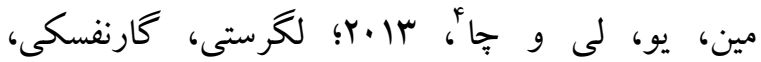

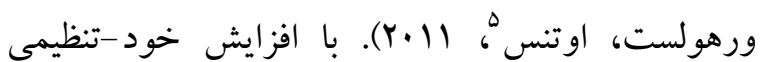
هيجانى فرد، استرس، افسردگى و اضطراب وى نيز كاهش مىيابد، زنان باردارى كه شرايط حاملكى براى بسيارى از آنها غيرقابل كنترل بوده و با برخى از علائم

\footnotetext{
1. Li, Zhu, Yang, He, Yi, Wang, Zhang

2 - Duan, Liu, Xiao, Zhao, \& Zhu

${ }^{3}$ - Wang, Yi, He, Chen, Li, Yang, \& Zhu

${ }^{4}$ - Min, Yu, Lee, Chae

5 - Legerstee, Garnefski, Verhulst, Utens
} 
هيجانى خود يكى از دلايل اثربخشى و مورد هدف قرار

دادن اين مؤلفه، به وسيله مداخلهى مورد نظر است. با مشاهده نتايج به دست آمده در گروه كنترل مشاهده مىشود كه سبك تنظيم هيجان فرد در طول زمان تقريباً با ثبات نسبى همراه است و حتى با وجود يايان باردارى و زايمان تغيير قابل توجهى در دشوارى تنظيم هيجان و يا بهبود آن صورت نخر فته است. با آموزش شناسايى ارزيابىهاى غلط و اثرات آنها روى حالتهاى هيجانى و آكَاهى از ارزيابى بردازش ذهنى و محتو اي ذهن خود و تأثير آن روى باسخ هاى هيجانى فرد و تمرينات آن، فرد در فضاى هيجانى منفى، حالتهاى هيجانى منفى را تجربه كرده و متعاقباً به ارزيابى شدت و و هردي

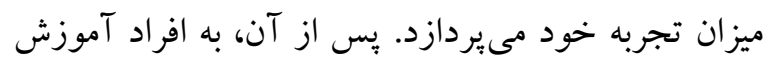

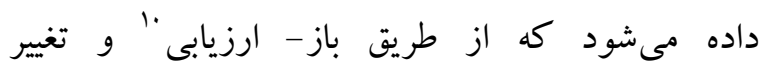

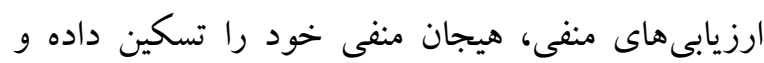
تنظيم كنند. باز -ارزيابى مثبت " به اتصال معناى مثبت به منيه رويداد منفى در زمينه رشد شخصى اشاره دارد

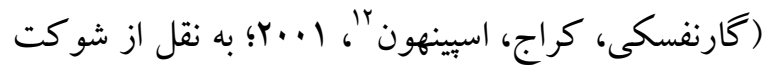

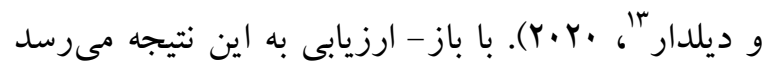
كه شرايطى كه در آن قرار گرفته است و استرس تجربه شده در اين مقطع عجيب نيست و مىتواند با شناخت هيجانات خود، آنها را كلامى كرده يا با مهارت حل

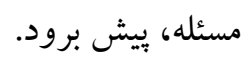

\section{نتيجه كيرى}

در مجموع نتايج حاكى از آن بود كه برنامهى آموزشى اجرا شده در بهبود كيفيت زندكى و دشوارى تنظيم r|r. (Y). اين مادر با يذيرش اضطراب خود در شرايط موجود و همجينين آرامسازى عضلانى (عدم دريافت بازخورد فيزيولوزيكى) و شناسايى راهبردهاى ناكار آمد،

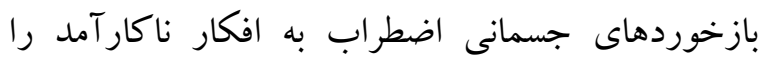
متوقف مى كند؛ بنابراين آموزش تنظيم هيجان از طريق

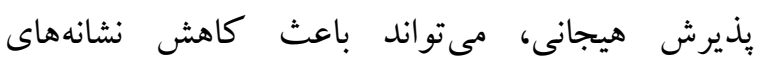
اضطراب و بهبود كيفيت زندكى شود (وان لارهون،

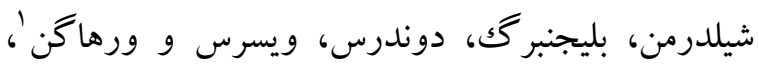
$(r+1)$ برنامه آموزشى تنظيم هيجان اجرا شده، توانسته است تنظيم هيجان زنان در دوران باردارى را به ميزان قابل توجهى بهبود بخشد كه اين يافته همسو با ساير بثزوهشهاى انجام شده است (مثل ويرتز، هافمن، ريير،

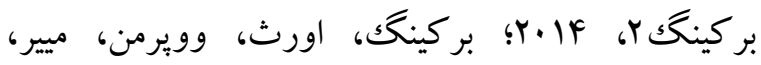

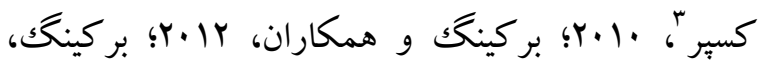

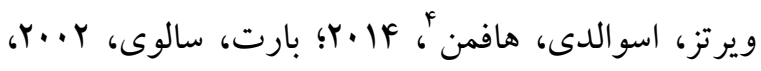

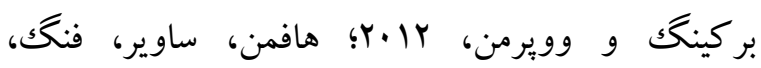

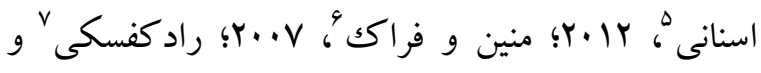

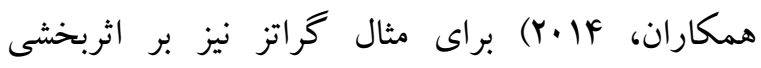
برنامهاى آموزشى مهارتهاى تنظيم هيجان بر خود تنظيمى هيجانى تأكيد كرده است (كراتز و گاندرسون؛

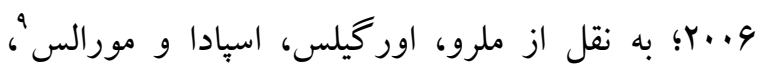
(Y.Y. باردار و در دوره يس از زايمان، وضعيت تنظيم هيجان بهبود يافته است. البته اين كاهش علائم دشوارى تنظيم

1. Van Laarhoven, Schilderman, Bleijenberg, Donders, Vissers, Verhagen

2- Wirtz, Hofmann, Riper, Berking

3 - Berking, Orth, Wupperman, Meier, Caspar

${ }^{4}$ - Berking, Wirtz, Svaldi, Hofmann

5 - Hofmann, Sawyer, Fang, Asnaani

${ }^{6}$ - Mennin, Farach

7 - Radkovsky

${ }^{8}$ - Gratz, Gunderson

9 - Melero, Orgilés, M, Espada, J.P. and Morales 


\section{References}

Abaszadeh F, Bagheri A, Mehran N. (2010). quality of life in pregnant women. payesh, 9(1), 69-75. (In Persian)

Arshad S, Shakoor A, Sadaf B. (2020). Chapter Ten Emotion Regulation and Self-Esteem Among Patients with Generalized Anxiety Disorder. Psychosocial Explorations of Gender in Society, P.144. (InPersian)

Asadi Mojre S, Akbari B. (2018). Aggressive structure based on emotion regulation, alexithymia, impulsivity and excitement in students. Sabzevar University of Medical Sciences (Asrar), 25(6), 828-819. (In Persian)

Azimi A, Omidi A, Shafiei E, Nademi A. (2018). The Effectiveness of Transdiagnostic, Emotionfocused Treatment for Emotional Regulation and Individual-social Adjustment in Female Students. J Arak Univ Med Sci, 20(10), 62-73. (In Persian)

Berking M, Orth U, Wupperman P, Meier LL, Caspar F. (2010). Prospective effects of emotionregulation skills on emotional adjustment. Journal of counseling psychology, 55(4), 485.

Berking M, Poppe C, Luhmann M, Wupperman P, Jaggi V, Seifritz E. (2012). Is the association between various emotion-regulation skills and mental health mediated by the ability to modify emotions? Results from two crosssectional studies. Journal of behavior therapy and experimental psychiatry, 43(3), 931-937.

Berking M, Wirtz CM, Svaldi J, Hofmann SG. (2014). Emotion regulation predicts symptoms of depression over five years. Behaviour Research and Therapy, 57, 13-20.

Berking M, Wupperman P. (2012). Emotion regulation and mental health: recent findings, current challenges, and future directions. Current opinion in psychiatry, 25(2), 128-134.

Bigizadeh S, Sharifi N, Javadpour S, Jamali S. (2020). Sexual function and quality of life in pregnant Iranian women. Sexual and Relationship Therapy, 1-9.(In Persian)

Brunton RJ, Dryer R, Saliba A, Kohlhoff J. (2015). Pregnancy anxiety: A systematic review of
هيجان مؤثر بوده است؛ لذا از نتايج اين يزوهش مىتوان نتيجه گرفت كه آموزش گروهى تنظيم هيجان به عنوان مداخلهاى براى كاهش مشكلات روانشناختى و بد تنظيمى هيجانى و بهبود كيفيت زندگى در دوران باردارى و يّ از زايمان مؤثر است. استفاده از يرسشنامه خود گزارشى براى سنجش متغيرها و همينطور نياز به به بـ حضور منظم زنان باردار در جلسات در ساعات مشخص از جمله محدوديتهاى اين بزوهش محسوب مىشود. با توجه اهميت سلامت روان و كيفيت زندكى در دوران باردارى، ئزوهش حاضر مى تواند، بلى بين بيزوهش هاى بنيادين و آزمايشى در حوزه روانشناسى زنان برقرار كرده و راه را براى كاربرد تكنيككهاى نوين تنظيم هيجان براى ترفيع سلامت روانشناختى اين افراد هموار كند. مداخلات مشابه مىتوانند با ايجاد فضايى كاربردى و بالينى در توسعه سلامت روان و بيشگيرى از اختلالات مادران و كود كان نقش مهمى داشته باشند. از سوى ديخر مطالعه حاضر به دليل گروهى بودن مىتواند در سطح كلان اجرا شده و از نظر مالى براى مخاطبين و نهادهايى كه سعى در بيشخيرى مشكلات سلامت روان بهخصوص در دوران باردارى و يس از زايمان دارند بهصرفه باشد. سياسگز ارى اين مقاله بركرفته از ياياننامه ارشد است. اين بثزوهش در كميته اخلاق دانشخاه علوم يزشكى شهيد بهشتى با كد اخلاق IR.SBMU.MSR.REC.1397.442 مورد تائيد قرار گرفته است. همجِنين لازم به ذكر هست كه هيج يكك از نو يسند كان اين بزوهش، تعارض منافعى براى

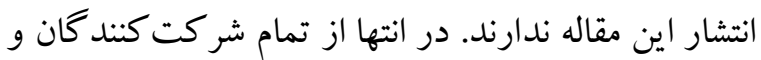
افرادى كه ما را در انجام اين بُزوهش كمكك كردند

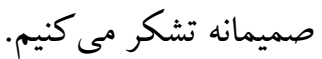


current scales. Joumal of affective disorders. 176:24-34.

Cancian ACM, Souza LASD, Machado WDL, Oliveira MDS. (2019). Psychometric properties of the Brazilian version of the Difficulties in Emotion Regulation Scale (DERS). Trends in psychiatry and psychotherapy, 41(1), 18-26.

Cattaruzza A. (2014). Difficulties in the treatment of depression during pregnancy and postpartum depression. Journal of Infant, Child, and Adolescent Psychotherapy, 13(1), 75-87.

Duan S, Liu Y, Xiao J, Zhao S, Zhu X. (2011). Cognitive emotion regulation questionnaire in hypertensive patients. Zhong nan da xue xue bao. Yi xue ban= Journal of Central South University. Medical sciences, 36(6), 532.

Eskandari S, Heravi karimoy M, Rezhe N, Ebadi A, Montazeri A. (2015). Evaluation of the validity and reliability of a specific questionnaire to assess the quality of life of patients with heart failure. Joumal of Jahad University Research Institute of Health Sciences, 14(4), pp. 475-484. (In Persian)

Garnefski N, Van Den Kommer T, Kraaij V, Teerds J, Legerstee J, Onstein E. (2012). The relationship between cognitive emotion regulation strategies and emotional problems: comparison between a clinical and a non- clinical sample. European journal of Personality, 16(5), 403-420.

Gilanifar M, Delavar MA. (2017). The relationship between alexithymia and general symptoms of pregnant women. Romanian Journal of Internal Medicine, 55(1), 14-18. (InPersian)

Gu M, Cheng Q, Wang X, Yuan F, Sam NB, Pan H, $\mathrm{Li} \mathrm{B}$, Ye D. (2019). The impact of SLE on health-related quality of life assessed with SF36: a systemic review and meta-analysis. Lupus, 28(3), pp.371-382.

Hofmann SG, Sawyer AT, Fang A, Asnaani A. (2012). Emotion dysregulation model of mood and anxiety disorders. Depression and Anxiety, 29(5), 409-416.

Hong JM. (2019). Persuasive effects of the four types of regulatory-focused message framing in philanthropy advertising (Doctoral dissertation).

Karami K, Mardani A, ShakeriNejad G, Saki A. (2015). Effectiveness of A Codified Educational Behavioral Program on the Mental Health of Pregnant Women. SSU_Journals. 23(9):879-89. (In Persian)

Koole SL. (2009). The psychology of emotion regulation: An integrative review. Cognition and emotion, 23(1), $4-41$.

Lausi G, Quaglieri A, Burrai J, Mari E, Giannini AM. (2020). Development of the DERS-20 among the Italian population: a study for a short form of the Difficulties in Emotion Regulation Scale. Mediterranean Journal of Clinical Psychology, 8(2).

Legerstee JS, Gamefski N, Verhulst FC, Utens EM. (2011). Cognitive coping in anxietydisordered adolescents. Journal of adolescence, 34(2), 319-326.

Li L, Zhu X, Yang Y, He J, Yi J, Wang Y, Zhang J. (2015). Cognitive emotion regulation: characteristics and effect on quality of life in women with breast cancer. Health and quality of life outcomes, 13(1), 51.

Lin Y, Yu Y, Zeng J, Zhao X, Wan C. (2020). Comparing the SF-36 and SF-12 in Psychometric Properties as Measuring Quality of Life among Adolescent in China: a Large Sample Cross-sectional Study.

Makvandi S, Etemadi KA. (2010). Quality of life in pregnant women who refered to ize health center in 2010.37-42. (In Persian)

Melero S, Orgiles M, Espada JP, Morales A. (2020). How depression facilitates psychological difficulties in children? The mediating role of cognitive emotion regulation strategies. Clinical Psychology \& Psychotherapy.

Mennin D, Farach F. (2007). Emotion and evolving treatments for adult psychopathology. Clinical Psychology: Science and Practice, 14(4), 329352.

Min JA, Yu JJ, Lee CU, Chae JH. (2013). Cognitive emotion regulation strategies contributing to resilience in patients with depression and/or 
anxiety disorders. Comprehensive psychiatry, 54(8), 1190-1197.

Moghaddam-Banaem L, Ahmadi F, Kazemnejad A. (2014). Iranian mothers' selection of a birth method in the context of perceived norms: A content analysis study. Midwifery 30(7):804 9. (InPersian)

Noorbala AA, Afzali HM, Abedinia N, Akhbari M, Moravveji SA, Shariat M. (2019). Investigation of the effectiveness of psychiatric interventions on the mental health of pregnant women in Kashan City-Iran: A clinical trial study. Asian journal of psychiatry, 46, 79-86. (In Persian)

Nordgren L, Monell E, Birgegård A, Bjureberg J, Hesser H. (2020). Factor structure of the difficulties in emotion regulation scale in treatment seeking adults with eating disorders. Journal of Psychopathology and Behavioral Assessment, 42(1), 111-126.

Pilkonis P. (2019). Difficulties in Emotion Regulation Scale (DERS)-Personality Studies.

Radkovsky A, McArdle JJ, Bockting CL, Berking M. (2014). Successful emotion regulation skills application predicts subsequent reduction of symptom severity during treatment of major depressive disorder. Journal of Consulting and clinical psychology, 82(2), 248.

Rouhe H, Salmela-Aro K, Toivanen R, Tokola M, Halmesmaki E, Ryding EL, Saisto T. (2015). Group psychoeducation with relaxation for severe fear of childbirth improves matemal adjustment and childbirth experience-a randomised controlled trial. Journal of Psychosomatic Obstetrics Gynecology, 36(1), 1-9.

Rozgonjuk D, Elhai JD. (2019). Emotion regulation in relation to smartphone use: Process smartphone use mediates the association between expressive suppression and problematic smartphone use. Current Psychology, pp.1-10.

Saber M, Tehrani H, Shojaizadeh D, Maleki Z, Esfandyarpoor R. (2013). Mental Health and
Exposure to Stressful Life Events of Nurses Working in Emergency Medical Service (ER 115). (In Persian)

Sattarpour F, Ahmadi E, Gharamaleki HB. (2014). Effectiveness emotion regulation training on reduction of symptoms depression students. Shenakht journal of psychology \& psychiatry, 1(1), 31-38. (In Persian)

Shouket H, Dildar S. (2020). Predictors of Orphanage Residents' Life Satisfaction: Basic Psychological Needs and Cognitive Emotion Regulation. Pakistan Journal of Psychological Research, pp.493-508. (InPersian)

Van Laarhoven HW, Schilderman J, Bleijenberg G, Donders R, Vissers KC, Verhagen CA, Prins JB. (2011). Coping, quality of life, depression, and hopelessness in cancer patients in a curative and palliative, end-of-life care setting. Cancer Nursing, 34(4), 302-314.

Wang Y, Yi J, He J, Chen G, Li L, Yang Y, Zhu X. (2014). Cognitive emotion regulation strategies as predictors of depressive symptoms in women newly diagnosed with breast cancer. Psycho- Oncology, 23(1), 9399.

Wirtz CM, Hofmann SG, Riper H, Berking M. (2014). Emotion regulation predicts anxiety over a five year interval: A cross lagged panel analysis. Depression and Anxiety, 31(1), 87-95.

Woodward IC, Shaffakat S, Domine VH. (2019). Exploring the Reservoirs of Drivers and Blockers (Conscious and Unconscious): Worldviews and Emotions. InExploring Leadership Drivers and Blockers (pp. 31-40). Palgrave Macmillan, Singapore.

Wrosch C. (2011). Self-regulation of unattainable goals and pathways to quality of life. The Oxford handbook of stress, health, and coping, 319333.

Zahedi M, Deris F. (2012). investigating quality of life in pregnant women in farokhshahr city in 2012. 63-69. (In Persian) 